\title{
Slide Valves for Single-Screw Expanders Working Under Varied Operating Conditions
}

\author{
Yuting Wu ${ }^{1,2, *}$, Ruiping Zhi ${ }^{1,2}$, Biao Lei ${ }^{1,2}$, Wei Wang ${ }^{1,2}$, Jingfu Wang ${ }^{1,2}$, Guoqiang Li ${ }^{1,2}$, \\ Huan Wang ${ }^{1,2}$ and Chongfang $\mathrm{Ma}^{1,2}$ \\ 1 Key Laboratory of Enhanced Heat Transfer and Energy Conservation of Ministry of Education, \\ College of Environmental and Energy Engineering, Beijing University of Technology, Beijing 100124, China; \\ zhiruiping@gmail.com (R.Z.); leibiao4151@163.com (B.L.); wangwei@bjut.edu.cn (W.W.); \\ jfwang@bjut.edu.cn (J.W.); guoqiang121913@126.com (G.L.); whuan@emails.bjut.edu.cn (H.W.); \\ machf@bjut.edu.cn (C.M.) \\ 2 Key Laboratory of Heat Transfer and Energy Conversion of Beijing Municipality, \\ College of Environmental and Energy Engineering, Beijing University of Technology, Beijing 100124, China \\ * Correspondence: wuyuting@bjut.edu.cn; Tel.: +86-10-6739-6663 (ext. 8323); Fax: +86-10-6739-2774
}

Academic Editor: Roberto Capata

Received: 14 April 2016; Accepted: 15 June 2016; Published: 23 June 2016

\begin{abstract}
This paper fully describes the working principle of slide valves in single-screw expanders (SSEs). A geometric analysis of suction and volume ratio slide valves is presented to determine the relations between volume ratio, suction closure volume, discharge opening volume and slide valves displacement. An organic Rankine cycle (ORC) thermodynamic model with SSE integrated with slide valves is developed to analyze the power output of SSE and the net power output of ORC system and variation law of slide valves displacement. Analysis of a typical ORC system under changing operating conditions shows that the power output of the expander and the net output power of the ORC system with slide valves are much better than those without slide valves. When the condensing temperature is $40^{\circ} \mathrm{C}$ and the waste availability is $80 \mathrm{~kW}$, the increase in output power and net output power are approximately $3.4 \mathrm{~kW}$ and $5 \mathrm{~kW}$, respectively. The presented geometric analysis of slide valves and the thermodynamic model integrated with slide valves can be used to provide a theoretical and technical basis for designing the slide valves of SSEs and the control strategies of slide valves under varied operating conditions.
\end{abstract}

Keywords: slide valve; single-screw expander; organic Rankine cycle (ORC); part-load

\section{Introduction}

With increasing concerns about energy shortages and environmental pollution, low-grade waste heat recovery technology for power generation has received much attention in the past decades. Various low-grade heat recovery technologies have been developed and are currently employed in diverse applications such as solar thermal power [1], geothermal energy [2,3], biomass energy [4,5], and engine exhaust gases [6]. Among existing technologies, the organic Rankine cycle (ORC) is the most widely utilized because of its simplicity, reliability and cost-effectiveness [7].

As a power output machine, the expander plays an important role in the ORC system. Expanders come in two types: dynamic (turbine) [8,9] and positive displacement (volumetric) [10] such as rotary vane [11-14], scroll [15-19], twin screw [20], single-screw [21-27] and reciprocating expanders [28]. In the medium-low power range, the displacement expander is a better choice than the turbo generator, because the former has a low flow rate, low rotational speed and a high pressure ratio [29]. In the development of expander technologies for small-scale ORC units, the single-screw expander (SSE) has gained popularity because of its superior characteristics of balanced loads, small 
noise, long life service, little vibration, and simple structure [21-27]. SSE is a good choice for power generating ORC units ranging from $1 \mathrm{~kW}$ to $1000 \mathrm{~kW}$.

In practice, the ORC systems often work under varied operating conditions. As a result, SSEs operate under changing operation conditions. There are two main factors affecting the operating conditions of ORC systems and SSEs. One factor is waste heat fluctuation. Waste heat fluctuation leads to different flow rates of the working fluid in the evaporator, so the volumetric flow rate of the working fluid at the SSE inlet changes and the rotational speed of the SSE becomes unsteady because of the changing volume flow rate of the working fluid at the inlet. The efficiency of the SSE and ORC system decreases due to the serious leakage and increased friction caused by the unsteady rotational speed of SSE. The other is the different environmental temperatures caused by the seasonal changes. An environmental temperature fluctuation of $40{ }^{\circ} \mathrm{C}$ throughout a year is a commonplace phenomenon in many regions [30]. This fluctuation causes variations in the back pressure and pressure ratio of SSEs, so the pressure ratio does not match the optimum pressure ratio. Hence, over-expansion or under-expansion loss occurs to some extent for SSEs designed for a fixed volume ratio, and such a loss reduces the efficiency of SSEs and ORC systems. Therefore, developing a method to allow SSEs to operate properly at a certain constant rotational speed with a varying volume ratio under varied operation conditions is important to improve ORC efficiency.

Studies conducted on SSEs are mainly limited to experimental work, although some SSE prototypes have been built and tested. Wang et al. [22,23] conducted a series of performance tests on a SSE prototype with $117 \mathrm{~mm}$ diameter rotors using compressed air as the working fluid. The experimental results showed that the performance of the prototype was acceptable. Based on comparison between the performance of prototypes with different gate rotor/shell and screw/shell gaps, they concluded that the prototype with a medium gate rotors/shell gap of $0.04 \mathrm{~mm}$ and a screw/shell $0.05 \mathrm{~mm}$ gap demonstrates the best overall performance, with an expander shaft efficiency of $60 \%$. He et al. [24] investigated the influence of intake pressure on the performance of a self-developed SSE with a $175 \mathrm{~mm}$ diameter rotor. Aside from obtaining the performance parameters of the SSE from a test, they discovered a negative effect of high backing pressure values on the power output. Zhang et al. [25] conducted an experimental study on the influence of rotational speed on the performance of an air-powered SSE prototype with a $175 \mathrm{~mm}$ diameter rotor. The optimum performance of the prototype was obtained at an intake pressure of $15 \mathrm{bar}$, at which the variations in torque, power output and overall efficiency of the SSE were analyzed respect to the rotational speed. Zhang et al. [26] established an experimental test-bench for a diesel engine-ORC combined system by using SSEs with $155 \mathrm{~mm}$ diameters. The ORC and SSE performances were investigated under different diesel working conditions and SSE torques. The results showed that the maximum ORC efficiency was $6.48 \%$ when the output power of diesel engine was $250 \mathrm{~kW}$ and the SSE torque was $64.43 \mathrm{Nm}$. Desideri et al. [27] tested the performance of an ORC system with a reverse single-screw compressor serving as expander in low-grade waste heat recovery with two different working fluids, SES36 and R245fa. They found that the maximum electrical isentropic efficiencies of the system with SES36 and R245fa were $60 \%$ at $3000 \mathrm{rpm}$ and a pressure ratio of 8.8 and $52 \%$ at $3000 \mathrm{rpm}$ and a pressure ration of 6.8 , respectively.

As revealed by previous experimental studies, working condition changes consequently change the optimum operating point related to the rotational speed and pressure ratio for SSEs with a fixed built-in volume ratio. Conventional SSEs cannot be guaranteed to operate with a high efficiency point when the operating point differs from the optimum operating point. To improve the efficiency of SSEs under varied operating conditions, the first step is to make an SSE with a fixed rotational speed to fit the flow rate changes of working fluid. The second step is to find an optimum pressure ratio to eliminate under-expansion or over-expansion losses. However, there is no available literature regarding how to design a SSE with optimum rotational speed and variable built-in volume ratio to improve the performance of SSEs under varied operating conditions. 
In this study, slide valves were used to adjust the rotational speed and built-in volume ratio of SSEs so that the expander can adapt to changing working conditions. The geometric analysis provided below is expected to provide a theoretical and technical basis to develop suitable slide valves for SSEs working under such varied operating conditions.

\section{Slide Valve}

As shown in Figure 1, the entire working process of an SSE is divided into three phases, i.e., the suction, the closed expansion and the discharge. In the suction process, the suction closure volume $V_{\mathrm{scv}}$ of SSE gradually increases with the increase in the rotary angle of the gate rotor. When the rotary angle of the gate rotor increases to the suction ending angle $\theta_{\mathrm{se}}$, the suction process ends, and the closed expansion process begins. The basic volume continues to increase until the rotary angle of the gate rotor approaches the discharge starting angle $\theta_{\mathrm{ds}}$. At this time, the closed expansion closure volume reaches the highest point (discharge opening volume $V_{\text {dov }}$ ). Then the expander begins to discharge.

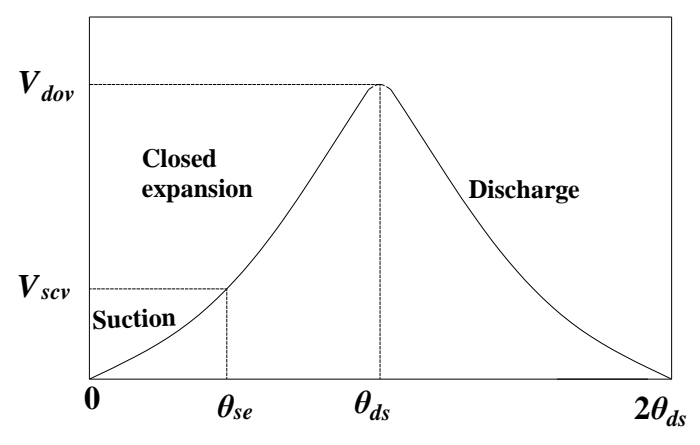

Figure 1. Simplified working process diagram of SSE.

A suction slide valve is introduced to adjust the suction closure volume $V_{\mathrm{scv}}$. A suction slide valve is a slide valve that can move in the axial direction between the single-screw rotor and the gate rotor, and can control the suction closure volume by changing the axial displacement of the suction slide valve. A volume ratio slide valve is introduced to change discharge opening volume $V_{\mathrm{dov}}$. This slide valve can move in the axial direction between the single-screw rotor and the gate rotor, but it controls the discharge opening volume by varying the axial displacement of the volume ratio slide valve.

Both the suction and the volume ratio slide valves themselves constitute part of the housing. The inner side of the two valves is fitted with the top circle of single-screw rotor. And their outer side of them is fitted with the housing. The two slide valves can move freely in the axial direction, and their movement is usually controlled by a hydraulic system.

In Figure 2a,b, the blue slide valve is the suction slide valve and the red one is the volume ratio slide valve. In Figure 2a, the suction and the volume ratio slide valves are assumed to be located at the design position. Equation (1) shows that if the inlet flow decreases, suction closure volume $V_{s c v}$ needs to decrease to maintain a stable SSE speed. Hence, the suction slide valve moves leftwards in the axial direction, as shown in Figure 2b. Equation (2) shows that discharge opening volume $V_{d o v}$ is required to decrease to obtain the same volume ratio. Thus, the volume ratio slide valve moves leftwards in the axial direction, as shown in Figure 2b:

$$
\begin{gathered}
\dot{V}_{\mathrm{in}}=2 n z_{1} V_{\mathrm{scv}} \\
\tau_{i}=\frac{V_{\mathrm{dov}}}{V_{\mathrm{scv}}}
\end{gathered}
$$




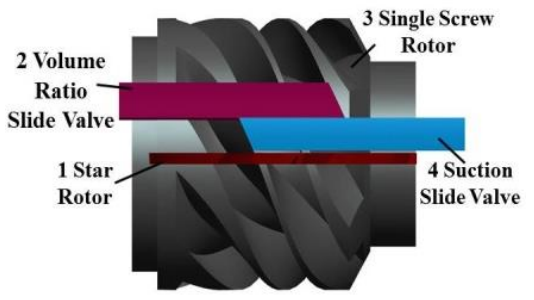

(a)

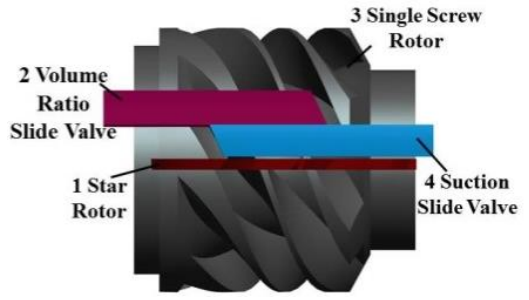

(b)

Figure 2. Structural diagram of slide valves. (a) Slide valves at the designed position. (b) slide valves at the position of decreased suction closure volume/discharge opening volume.

\section{Geometric Analysis of Slide Valve}

The slide valve configuration shows that the suction closure volume and discharge opening volume can be changed by varying the axial displacement of the suction and volume ratio slide valves. Hence a geometric analysis of slide valves is highly important to establish proper relationships between slide valve displacement and suction closure volume $V_{\mathrm{scv}}$ (or discharge opening volume $V_{\mathrm{dov}}$ ).

\subsection{Key Angles Related to Slide Valve Displacement}

The suction closure volume or discharge opening volume can be changed by changing the suction ending angle $\theta_{\mathrm{se}}$ and discharge starting angle $\theta_{\mathrm{ds}}$. When the slide valve moves a certain distance rightwards or leftwards, the suction ending angle $\theta_{\mathrm{se}}$ or the discharge starting angle $\theta_{\mathrm{ds}}$ are changed. Slide valve displacement is related to both the back and front helixes. The suction ending angle is related to the back helix. The discharge starting angle is related to the front helix.

As shown in Figure 3, the back helix is the intersection curve of the right surface of a screw groove and the side surface of the screw rotor. The front helix is the intersection curve of the left surface of a screw groove and the side surface of the screw rotor. The back and the front helix spread drawing are shown in Figure 4. The back and front helixes can be obtained as follows:

$$
\begin{gathered}
\text { Back helix : }\left\{\begin{array}{c}
y_{B H}=\left(C-r_{1}\right) \tan \theta+b / 2 \cos \theta \\
s=i r_{1} \theta \pi / 180
\end{array}\right. \\
\text { Front helix : }\left\{\begin{array}{c}
y_{F H}=\left(C-r_{1}\right) \tan \theta-b / 2 \cos \theta \\
s=i r_{1} \theta \pi / 180
\end{array}\right.
\end{gathered}
$$

where, $\theta$ stands for the rotary angle of the gate rotor, $\Delta y_{\mathrm{BH}}$ stands for the moving distance of suction slide valve, $\Delta \mathrm{y}_{\mathrm{FH}}$ represents for the moving distance of volume ratio slide valve. The initial positions of suction and volume slide valve are written as $\left(y_{\mathrm{BH} 0}, s_{\mathrm{BH}}\right)$ and $\left(y_{\mathrm{FH} 0}, s_{\mathrm{FH} 0}\right)$. Hence, when the suction and the volume ratio slide valve move by $\Delta y_{B H}$ and $\Delta y_{F H}$, respectively, suction ending angle $\theta_{\text {se }}$ and discharge staring angle $\theta_{\mathrm{ds}}$ can be calculated as:

$$
\begin{aligned}
& \theta_{\mathrm{se}}=\left\{\begin{array}{l}
\arccos \left(\frac{0.5 b}{\sqrt{\left(C-r_{1}\right)^{2}+\left(y_{\mathrm{BH} 0}+\Delta y_{\mathrm{BH}}\right)^{2}}}\right)-\arctan \left(\frac{C-r_{1}}{y_{\mathrm{BH} 0}+\Delta y_{\mathrm{BH}}}\right) ; \Delta y_{\mathrm{BH}} \text { towards left } \\
\arccos \left(\frac{0.5 b}{\sqrt{\left(C-r_{1}\right)^{2}+\left(y_{\mathrm{BH}}+\Delta y_{\mathrm{BH}}\right)^{2}}}\right)-\arctan \left(\frac{C-r_{1}}{y_{\mathrm{BH}}-\Delta y_{\mathrm{BH}}}\right) ; \Delta y_{\mathrm{BH}} \text { towards right }
\end{array},\right. \\
& \theta_{\mathrm{ds}}=\left\{\begin{array}{l}
\arccos \left(\frac{-0.5 b}{\sqrt{\left(C-r_{1}\right)^{2}+\left(y_{\mathrm{FH} 0}+\Delta y_{\mathrm{FH}}\right)^{2}}}\right)-\arctan \left(\frac{C-r_{1}}{y_{\mathrm{FH} 0}+\Delta y_{\mathrm{FH}}}\right) ; \Delta y_{\mathrm{FH}} \text { towards left } \\
\arccos \left(\frac{-0.5 b}{\sqrt{\left(C-r_{1}\right)^{2}+\left(y_{\mathrm{FH} 0}-\Delta y_{\mathrm{FH}}\right)^{2}}}\right)-\arctan \left(\frac{C-r_{1}}{y_{\mathrm{FH} 0}-\Delta y_{\mathrm{FH}}}\right) ; \Delta y_{\mathrm{FH}} \text { towards right }
\end{array},\right.
\end{aligned}
$$

where, $b$ is the tooth width of gate rotor; $C$ stands for the center distance between single-screw rotor and gate rotor; $r_{1}$ is the radius of single-screw rotor. 


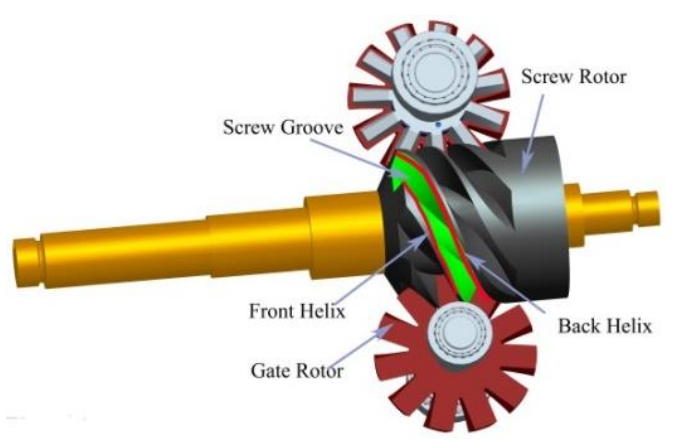

Figure 3. Structural diagram of SSE.

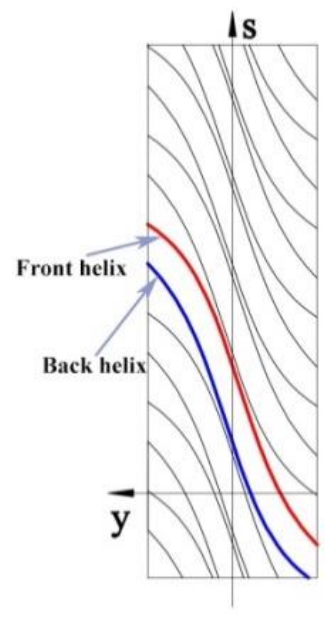

Figure 4. Helix spread of the screw rotor.

\subsection{Mathematical Modeling of the Suction Closure/Discharge Opening Volume}

The geometric relationships of SSE are illustrated in Figure 5. The entire expansion process of an SSE is divided into three phases, i.e., suction, closed expansion and discharge.

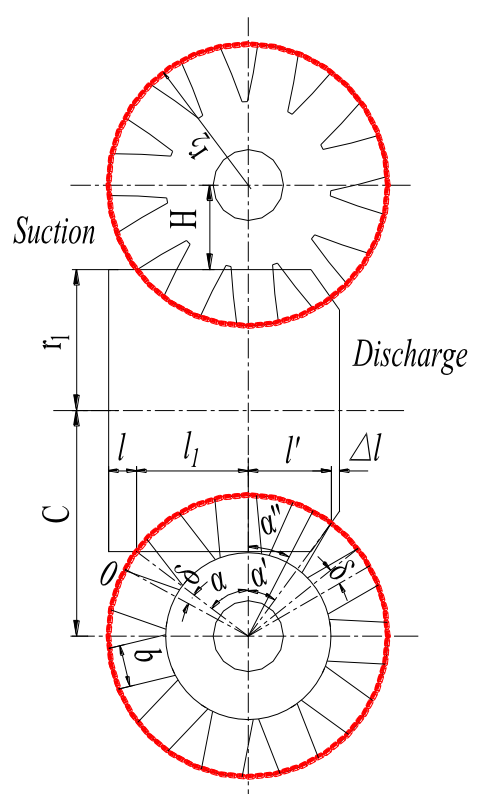

$$
\begin{aligned}
& \mathrm{r}_{2}=k_{0} \mathrm{r}_{1} \text {; generally } k_{0} \text { is equal to } 1 \text { or } 1.1 \text {. } \\
& H=k r_{1} ; k \text { ranges from } 0.2 \text { to } 0.9 \text {; } \\
& i=z_{2} / z_{1} \\
& l=\mathrm{r}_{1} \sqrt{2 k_{0} k-k^{2}} \\
& \alpha=\arcsin \left(\sqrt{2 k_{0} k-k^{2}} / k_{0}\right. \\
& \alpha^{\prime}=\arcsin \left(0.7 \sqrt{2 k_{0} k-k^{2}} / k_{0}\right. \\
& b=2 \mathrm{r}_{1}\left(k_{0}-k\right) \sin \left(\pi / z_{2}\right)-e \cos \left(\pi / z_{2}\right) \\
& b_{\mathrm{s}}=b / 2 \mathrm{r}_{2} \\
& \delta=\arcsin \left(b_{\mathrm{s}}\right)
\end{aligned}
$$

Figure 5. Geometric relationships of SSE. 
The suction closure volume is the groove volume that gate rotor tooth sweeps when the gate rotor rotates from 0 to $\theta_{\mathrm{se}}$. The expander suction closure volume can be calculated as:

$$
V_{\mathrm{scv}}=\int_{0}^{2 \delta} A i \overline{R_{1}} d \theta_{2}+\int_{2 \delta}^{\theta_{\mathrm{se}}} A i \overline{R_{1}} d \theta_{2}
$$

where, $A$ represents the meshing area of a gate rotor tooth; $\theta_{\text {se }}$ stands for the suction ending angle; $i=z_{2} / z_{1} ; z_{2}$ is the number of teeth of the gate rotor; and $z_{1}$ is the number of grooves of single-screw rotor.

The discharge opening volume is the groove volume that gate rotor tooth sweeps when the gate rotor rotates from 0 to $\theta_{\mathrm{ds}}$. The discharge opening volume formula can be written as:

$$
V_{d o v}=\int_{0}^{2 \delta} A i \overline{R_{1}} d \theta_{2}+\int_{2 \delta}^{\theta_{\mathrm{ds}}} A i \overline{R_{1}} d \theta_{2}
$$

where:

$$
A=\left\{\begin{array}{c}
A_{2 \delta}\left(\frac{\theta_{2}}{2 \delta}\right)^{2}, 0 \leqslant \theta_{2} \leqslant 2 \delta \\
\int_{-\frac{b}{2}}^{\frac{b}{2}}\left(\sqrt{k_{0}^{2} r_{1}^{2}-x^{2}}-\left(k_{0} r_{1}-H\right) \sec \theta_{2}+x \tan \theta_{2}\right) d x, 2 \delta \leqslant \theta_{2} \leqslant \alpha+\delta+\alpha^{\prime \prime} . \\
A_{2 \delta}=k_{0}^{2} r_{1}^{2} \arcsin \left(b_{\mathrm{s}}\right)+b_{s} \sqrt{1-b_{\mathrm{s}}^{2}}-2 b_{\mathrm{s}} k_{0} r_{1}^{2}\left(k_{0}-k\right) \sec (2 \delta)
\end{array}\right.
$$

The relationships between the displacement of the slide valve and the suction closure volume, the discharge opening volume and volume ratio have been outlined based on the mathematical modeling above. In the following figures, $\Delta y / d_{1}$ represents the displacement of the slide valve with respect to the screw rotor diameter; $V_{\mathrm{scv}} / d_{1}^{3}$ is the suction closure volume with respect to the cube of screw rotor diameter; $V_{\text {dov }} / d_{1}^{3}$ is the discharge opening volume with respect to the cube of screw rotor diameter. As shown in Figure 6, as the suction slide valve moves to the left, the suction closure volume decreases. It is visible from Figure 7 that there was a decrease of discharge opening volume with the leftward moving distance of the volume ratio slide valve. It can be seen from Figure 8 that, when the discharge opening volume is constant, the volume ratio shows an exponential decay with the leftward moving distance of the suction slide valve. As displayed in Figure 9, when the suction closure volume is fixed, the volume ratio approximately decreases quasi-linearly with the leftward moving distance of the volume ratio slide valve.

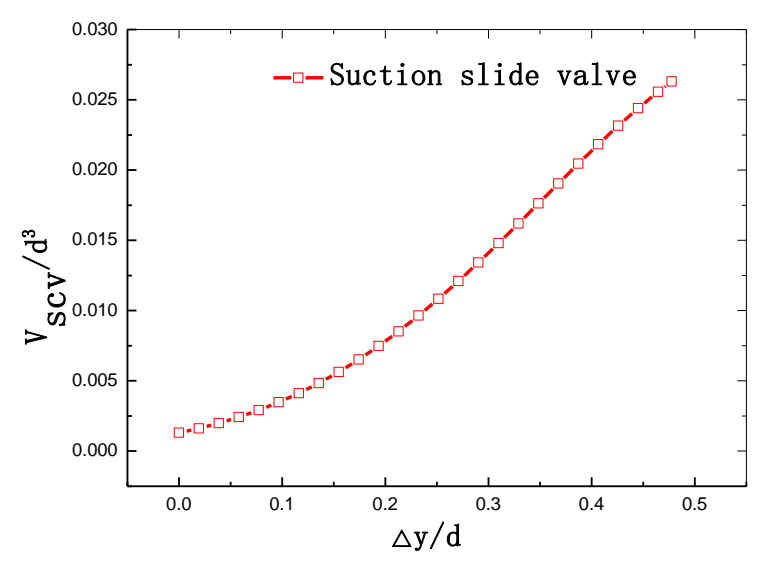

Figure 6. $V_{\mathrm{scv}} / d_{1}^{3}$ vs. $\Delta y / d_{1}$ of suction slide valve. 


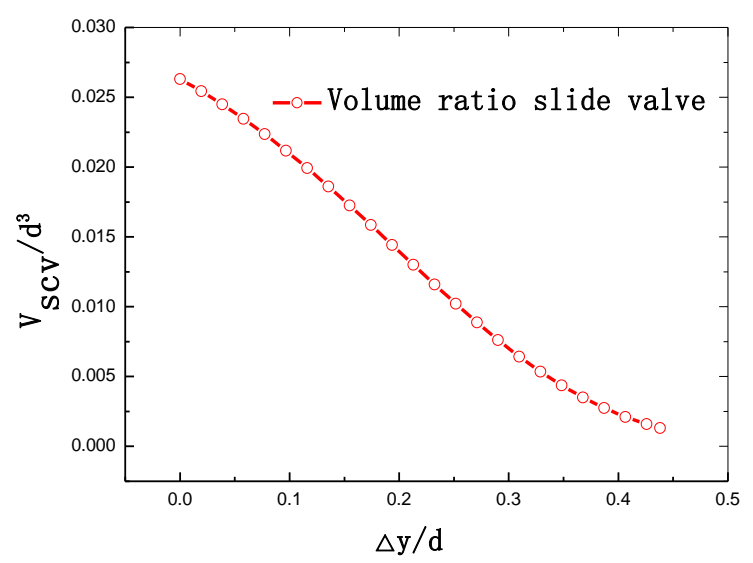

Figure 7. $V_{\mathrm{dov}} / d_{1}^{3}$ vs. $\Delta y / d_{1}$ of volume ratio slide valve.

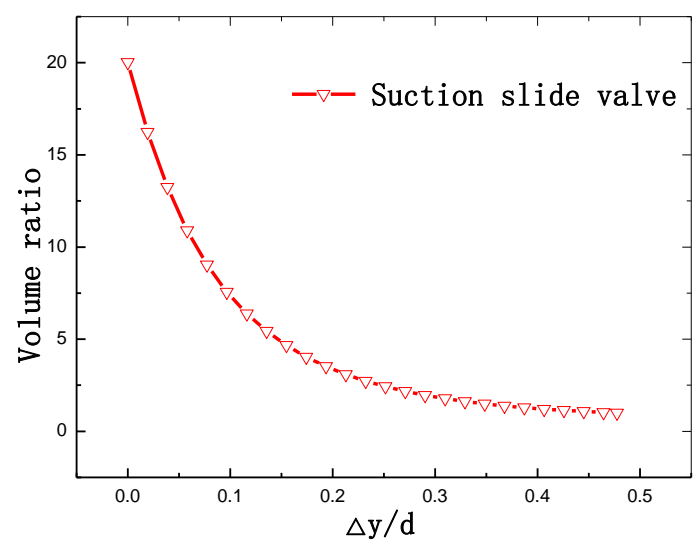

Figure 8. Volume ratio vs. $\Delta y / d_{1}$ of suction slide valve.

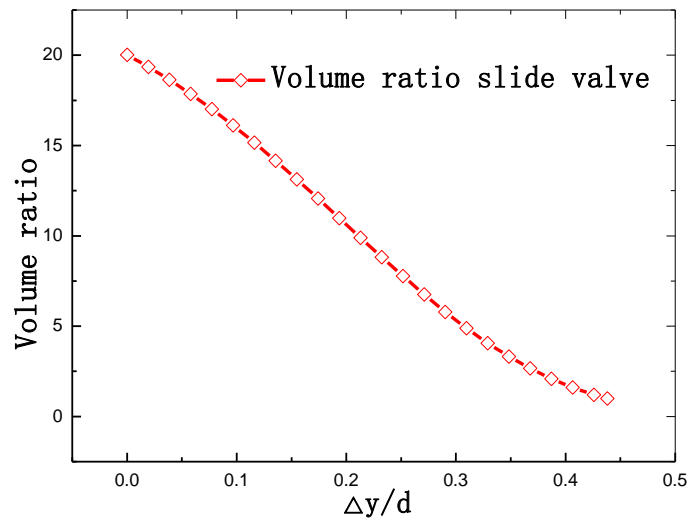

Figure 9. Volume ratio vs. $y / d_{1}$ of volume ratio slide valve.

\section{Thermodynamic Model of the ORC System Based on SSE Integrated with Slide Valves}

As shown in Figure 10, this ORC system is mainly composed of an evaporator, an SSE, a condenser and a pump. The SSE serves as an output power machine. The working fluid is R123. The T-s diagram of the ORC system is shown in Figure 11. 


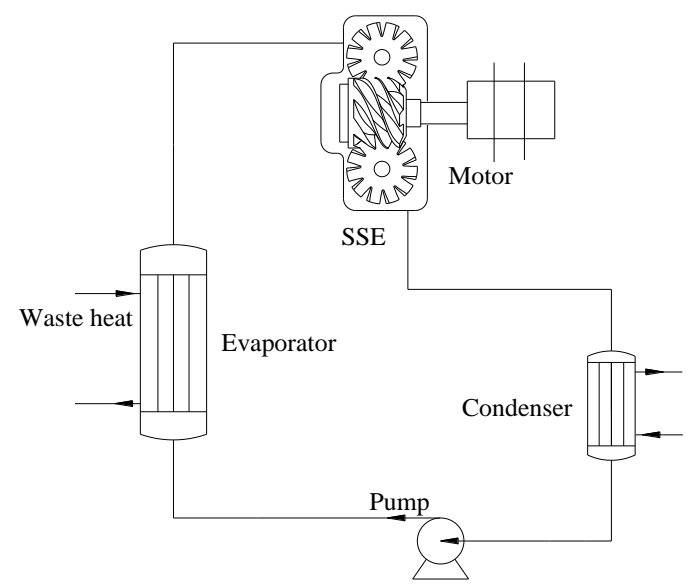

Figure 10. ORC system diagram.

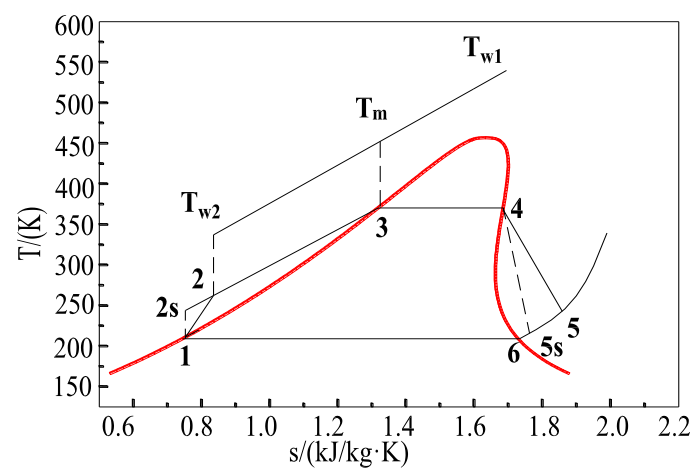

Figure 11. T-s diagram of the ORC system.

The working fluid is heated in the evaporator by waste heat, and turns into vapor under high temperature and high pressure. This process is the isobaric endothermic process of the working fluid in the evaporator (evaporation process 2-4 in Figure 11). Then the vapor expands in the SSE to produce work and turns into vapor with low pressure and low temperature. This process $4-5$ in Figure 11 is the corresponding expansion process. Process $4-5$ is the isentropic expansion process. The vapor with low temperature and pressure flows into the condenser and releases the heat so that the working fluid transformed back into liquid. This process is $5-1$ condensing process in Figure 11. Finally the working fluid is sent into the evaporator by the pump (1-2 compression process and $1-2 \mathrm{~S}$ isentropic compression process in Figure 11) and the cycle is completed.

According to the energy conservation principle and assuming that the heat transfer losses in the heat exchangers are disregarded, the released heat by waste heat is equal to the heat absorbed by working fluid in the evaporator. When the working fluid is sent into the evaporator, the absorbed heat can be written as:

$$
\dot{Q}_{\mathrm{wf}}=\dot{Q}_{\mathrm{w}}=\dot{m}_{\mathrm{wf}}\left(h_{4}-h_{2}\right) .
$$

The volume flow rate of SSE can be obtained as:

$$
\dot{V}_{\mathrm{in}}=\frac{\dot{m}_{\mathrm{wf}}}{\rho\left(p_{4}, T_{4}\right)}=2 n z_{1} V_{\mathrm{sbv}} .
$$

The output power of SSE can be expressed as:

$$
\dot{W}_{\mathrm{sse}}=\dot{m}_{\mathrm{wf}} \eta_{\mathrm{s}}\left(h_{4}-h_{5 \mathrm{~s}}\right) \text {. }
$$


The pressure ratio and optimum pressure ratio can be explained as:

$$
\begin{gathered}
r_{\mathrm{p}}=\frac{p_{4}}{p_{5}}, \\
r_{\mathrm{opt}}=\left(\frac{V_{\mathrm{dov}}}{V_{\mathrm{scv}}}\right)^{\kappa} .
\end{gathered}
$$

In this study, the working fluid is R123. The exponent $\kappa$ is equal to 1.19 which is an empirical value. Without the slide valves, the shaft efficiency of SSE $\eta_{\mathrm{s}}$ can be estimated by an empirical formula Equation (14) given by Desideri et al. [31]. When a SSE is integrated with both suction and discharge slide valves, the rotational speed of SSE can be maintained at an optimum value and the pressure ratio can be adjusted at an optimum pressure ratio so that neither under expansion nor over expansion losses occurs. Hence, the shaft efficiency of SSE $\eta_{\mathrm{s}}$ is equal to the optimum shaft efficiency of expander $\eta_{\mathrm{opt}}$ :

$$
\eta_{\mathrm{s}}=y_{\max }\left(\xi \arctan \left(B\left(r_{\mathrm{p}}-r_{\mathrm{p}, 0}\right)-E\left(B\left(r_{\mathrm{p}}-r_{\mathrm{p}, 0}\right)-\arctan \left(B\left(r_{\mathrm{p}}-r_{\mathrm{p}, 0}\right)\right)\right)\right)\right)
$$

with:

$$
\begin{gathered}
B=\vartheta /\left(\xi, y_{\max }\right) \\
E=\left(B\left(\mathrm{r}_{\mathrm{p}, \max }-\mathrm{r}_{\mathrm{p}, 0}\right)-\tan (\pi / 2 \xi)\right) /\left(B\left(\mathrm{r}_{\mathrm{p}, \max }-\mathrm{r}_{\mathrm{p}, 0}\right)-\arctan \left(B\left(\mathrm{r}_{\mathrm{p}, \max }-\mathrm{r}_{\mathrm{p}, 0}\right)\right)\right) \\
r_{\mathrm{p}}^{*}=\frac{r_{\mathrm{p}}-4}{r_{\mathrm{p}}} ; N_{\mathrm{rot}}^{*}=\frac{N_{\mathrm{rot}}-3000}{3000} ; p^{*}=\frac{p-10}{10} \\
r_{\mathrm{p}, 0}=r_{\mathrm{p}, 0, \mathrm{n}}+a_{0} N_{\mathrm{rot}}^{*} \\
\vartheta=\vartheta_{\mathrm{n}}+a_{1} p^{*}+a_{2} N_{\mathrm{rot}}^{*} \\
r_{\mathrm{p}, \max }=r_{\mathrm{p}, \max , \mathrm{n}}+a_{3} p^{*}+a_{4} N_{\mathrm{rot}}^{*} \\
y_{\max }=y_{\max , \mathrm{n}}+a_{5} p^{*}+a_{6}\left(N_{\mathrm{rot}}^{*}-N_{\mathrm{rot}, \mathrm{n}}^{*}\right)^{2} \\
N_{\mathrm{rot}, \mathrm{n}}^{*}=\frac{N_{\mathrm{rot}, \mathrm{n}}-3000}{3000}
\end{gathered}
$$

where the parameters $r_{\mathrm{p}, 0}, \vartheta_{\mathrm{n}}, \xi, y_{\max , \mathrm{n}}$ and $N_{\text {rot, } \mathrm{n}}$ have a mathematical meaning described in Table 1.

Table 1. Parameters for efficiency model of SSE.

\begin{tabular}{lll}
\hline \multicolumn{1}{c}{ Performance } & \multicolumn{1}{c}{ Description } & Value \\
\hline$r_{\mathrm{p}, 0}$ & x-intercept of the efficiency curve as a function of the pressure ratio & 3.076 \\
$\vartheta_{\mathrm{n}}$ & Slope of the efficiency curve close to the x-intercept & 0.7924 \\
$\xi$ & Parameter setting the shape of the efficiency curve & 1.213 \\
$y_{\max , \mathrm{n}}$ & Maximum efficiency for the reference conditions & 0.592 \\
$r_{\mathrm{p}, \text { max } \mathrm{n}}$ & Optimal pressure ratio for the reference conditions & 10 \\
$N_{\text {rot, } \mathrm{n}}$ & Optimal rotational speed for the reference conditions & 3547 \\
\hline Empirical parameters & $a_{0}=0 ; a_{1}=0.8411 ; a_{2}=8.347 ; a_{3}=3 ; a_{4}=3 ; a_{5}=0.023383 ; a_{6}=0.4827$ \\
\hline
\end{tabular}

When the working fluid with low pressure enters the pump, the compressibility of the working fluid can be disregarded. Thus, the power consumption of the pump can be written as:

$$
\dot{W}_{\mathrm{p}}=\frac{v \int_{1}^{2} d p}{\eta_{\mathrm{p}}}=\frac{v\left(p_{1}-p_{2}\right)}{\eta_{\mathrm{p}}} .
$$

According to a previous work [32], pump efficiency is very low when the fluid is organic. Hence, pump efficiency $\eta_{\mathrm{p}}$ is set to 0.25 . 
The net power output of the ORC system can be written as:

$$
\dot{W}_{\text {net }}=\dot{W}_{\mathrm{sse}}-\dot{W}_{\mathrm{p}}=\frac{\dot{Q}_{\mathrm{wf}} \eta_{\mathrm{s}}\left(h_{4}-h_{5 \mathrm{~s}}\right)}{h_{4}-h_{2}}-\frac{v\left(p_{1}-p_{2}\right)}{\eta_{\mathrm{p}}} .
$$

Based on the thermodynamic model of ORC with SSE integrated with slide valves as expander, the calculation flow chart is displayed in Figure 12.

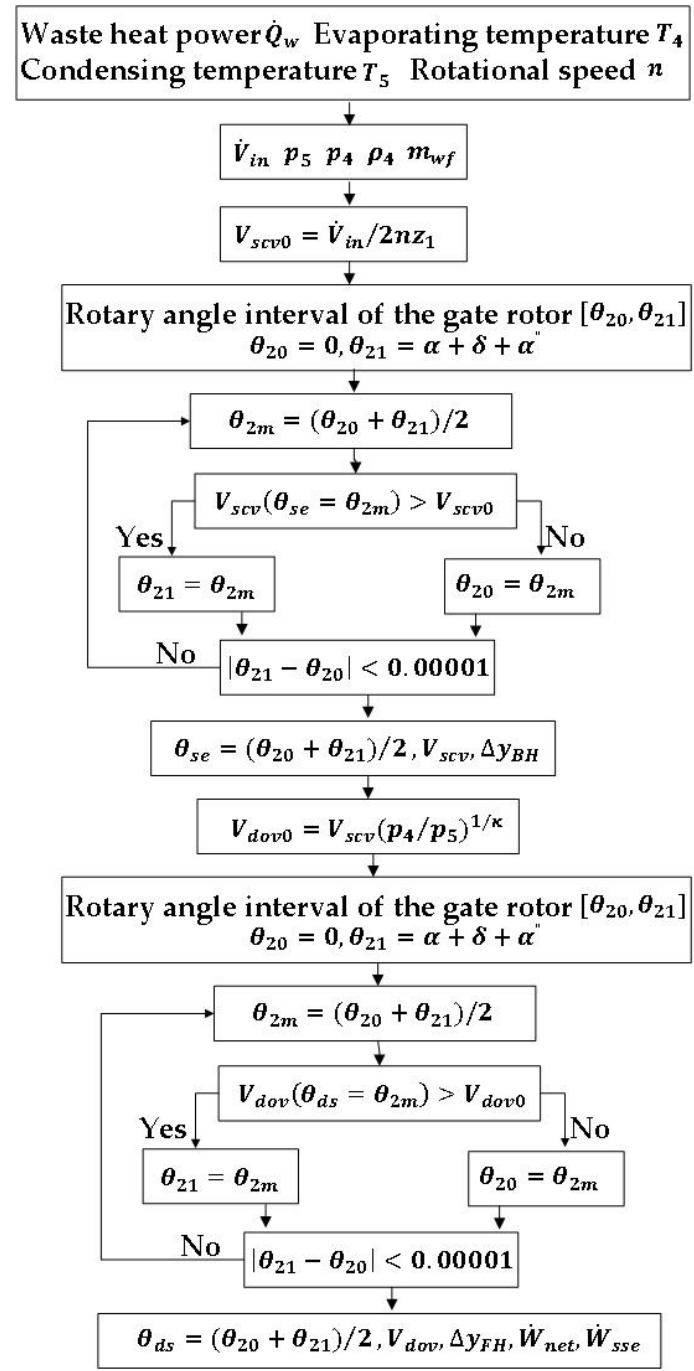

Figure 12. Flow chart of the calculation.

\section{Results and Discussion}

A SSE with a $155 \mathrm{~mm}$ diameter rotor is utilized to produce output power in a truck engine-ORC combined system and the main parameters are shown in Table 2. The tooth width of the gate rotor is $23.4 \mathrm{~mm}$. The design volume ratio is 5 . The rotary speed of the SSE adjusted by slide valves is maintained at $3000 \mathrm{rpm}$ and the optimum shaft efficiency is thought as $60 \%$. The original position of the suction slide valve is set as the positon where the volume ratio is 5 and the discharge opening volume is the biggest. The original position of the volume ratio slide valve is the position where the discharge opening volume reaches the highest value. When the working fluid R123 flows into SSE, it is saturated vapor at $120^{\circ} \mathrm{C}$ as assumed. When it flows out of the condenser, it is assumed to be at saturated condensing temperature. The condensing temperature ranges from $30^{\circ} \mathrm{C}$ to $40^{\circ} \mathrm{C}$. 
Table 2. Main parameters of SSE.

\begin{tabular}{ccc}
\hline Parameters & Units & Values \\
\hline Engaging ratio & $(-)$ & $11 / 6$ \\
Screw rotor diameter & $(\mathrm{mm})$ & 155 \\
Gate rotor diameter & $(\mathrm{mm})$ & 155 \\
Tooth width of gate rotor & $(\mathrm{mm})$ & 23.4 \\
Volume ratio (the initial position of slide valves) & $(-)$ & 5 \\
\hline
\end{tabular}

Now, SV represents the slide valve in the following figures. From Figures 13 and 14, it can be seen that, under the same condensing temperature, the power output of SSE and the net power output of ORC system with slide vales are greater than that of SSE without slide valves. Under the same condensing temperature, the increase in power output and net output power for ORC system and SSE by using slide valves become greater with decrease of waste heat availability. When the condensing temperature is $40^{\circ} \mathrm{C}$ and the waste availability is $80 \mathrm{~kW}$, the increase in output power and net output power is approximately $3.4 \mathrm{~kW}$ and $5 \mathrm{~kW}$, respectively. The suction slide valve makes the SSE run at a fixed speed and the volume ratio slide valve prevents it from under-expansion and over-expansion, and thus the SSE can work at a better efficiency point. After adding both the suction slide valve and the volume ratio slide valves for a SSE, the power output and the net power output increases linearly with the growth of waste heat availability, as can be seen from the power output and net power output equation, i.e., Equations (11) and (24). Therefore, the power output of SSE and the net power output $\dot{W}_{\text {net }}$ of ORC system with suction and volume ratio slide vales are proportional to the waste heat $\dot{Q}_{\mathrm{w}}$.

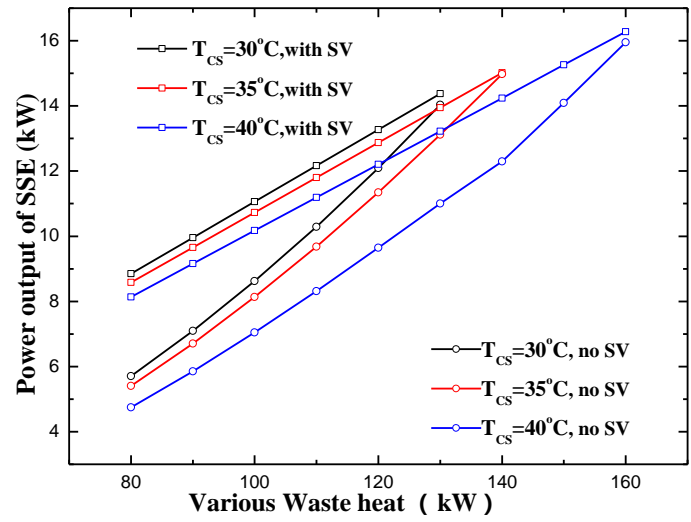

Figure 13. Power output of SSE vs. various waste heat.

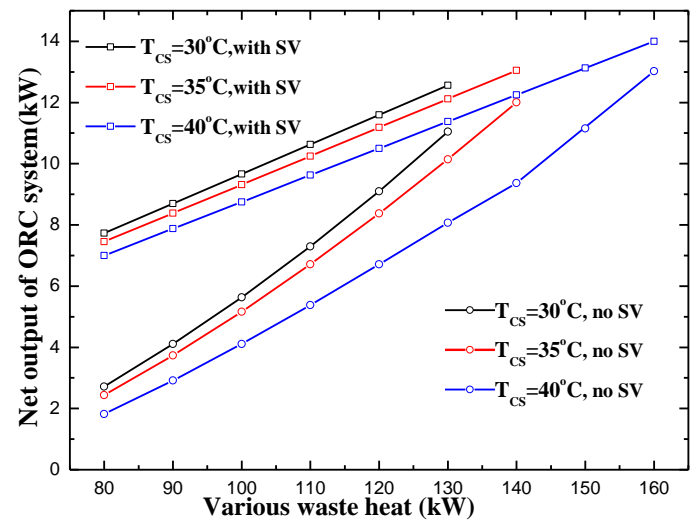

Figure 14. Net power output of the ORC system vs. various waste heat. 
As shown in Figures 15-18, at the same waste heat availability, there is an almost linear increase for the power output of SSE with slide valves with decrease of condensing temperature; and the net power output of ORC system with the suction slide valve and volume ratio slide valve also increases with decrease of condensing temperature and there is a nearly linear increasing trend. Equations (11) and (24) illustrate that, under the same amounts of waste heat, the net power output is mainly related to adiabatic enthalpy value $h_{5 s}$ and condensing pressure $p_{2}$. The adiabatic enthalpy value $h_{5 \mathrm{~s}}$ is also related to condensing pressure $p_{2}$ and inlet enthalpy of SSE.

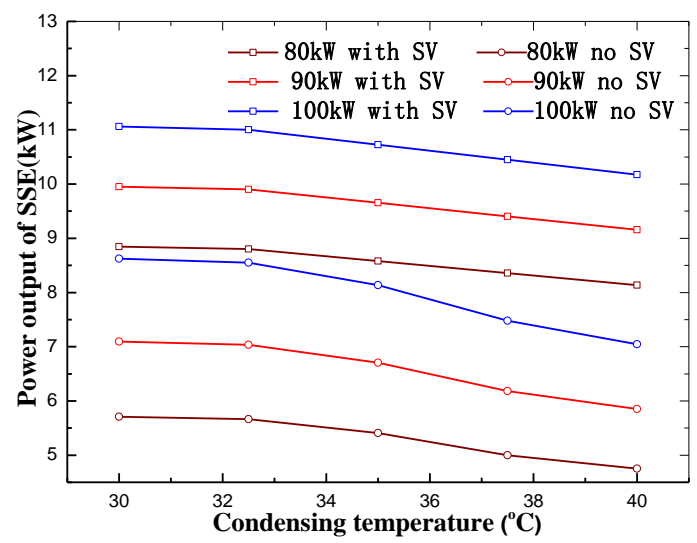

Figure 15. Power output of SSE vs. condensing temperature.

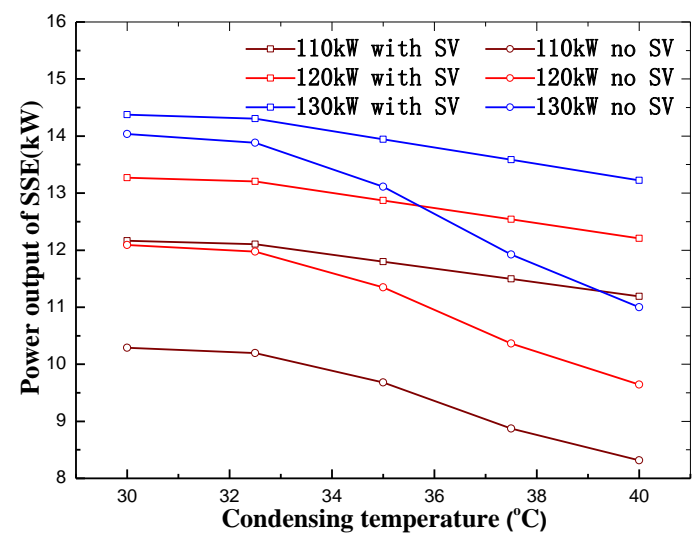

Figure 16. Power output of SSE vs. condensing temperature.

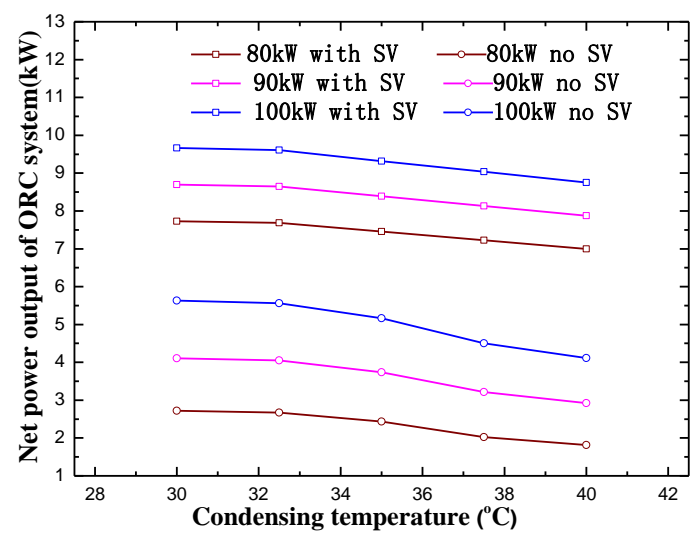

Figure 17. Net power output of ORC system vs. condensing temperature. 


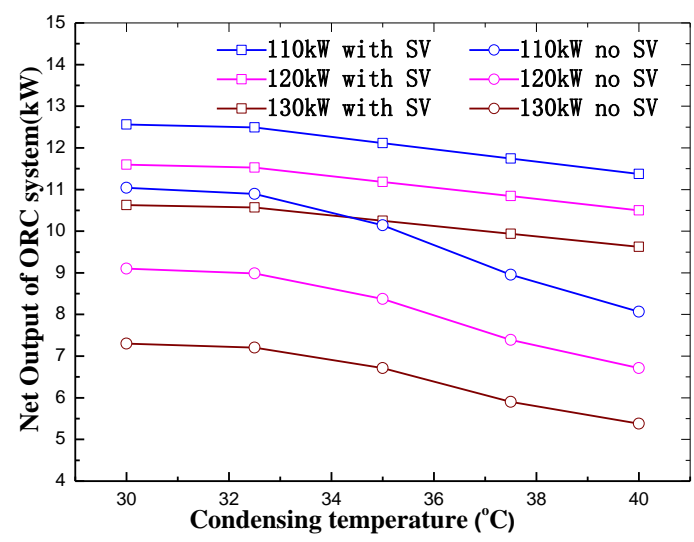

Figure 18. Net power output of ORC system vs. condensing temperature.

The evaporating pressure and temperature are assumed to be a fixed value, so the inlet enthalpy of SSE is also a constant. Therefore, the power output and net power output are mainly related to condensing pressure $p_{2}$. For this reason, the power output of expander and the net power output of the ORC system tend to change with the change in condensing temperature in a nearly linear manner. When the volume ratio is 5 , the position of the suction slide valve and volume ratio slide valve are set to the initial position. If the displacement of slide valve is greater than 0 , the slide valve moves towards left, and vice versa. As indicated in Figure 19, under a constant condensing temperature, with growth of waste heat, the leftward moving distance of the suction slide valve decreases approximately linearly and finally the slide valve moves toward right side of the design position. When the waste heat increases, there will be a growth for the volume flow rate of working fluid at the inlet of SSE. In order to maintain the stable speed of SSE, the suction closure volume needs to increase so that the suction ending angle needs to increase. Thus, the suction slide valve moves towards the direction that can increase the suction ending angle with increase in waste heat.

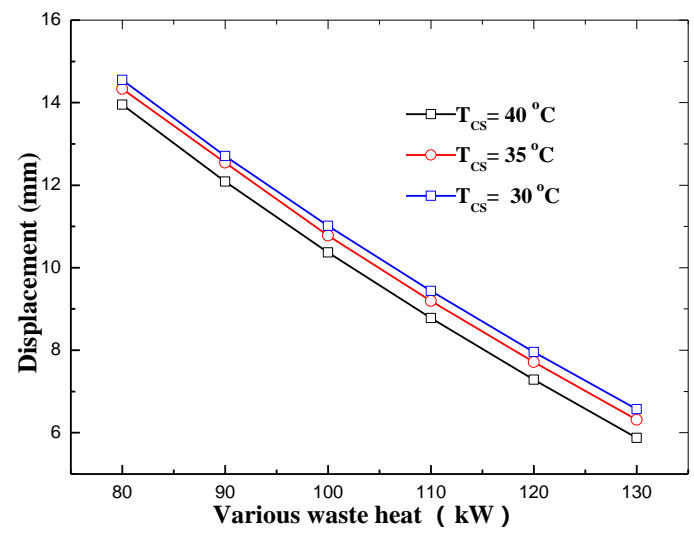

Figure 19. Displacement of suction slide valve vs. various waste heat.

As shown in Figure 20, under the same waste heat, a gradual decrease in the leftward moving distance of the suction slide valve occurs when the condensing temperature increases. When the condensing temperature increases, the enthalpy at the condenser outlet increases and the pump consumption decreases. However, the outlet enthalpy increment of the condenser is greater than the reduction of pump consumption. Thus, the inlet volume flow rate of SSE increases with increase in condensing temperature. In order to obtain a fixed speed, the suction closure volume needs to increase, which means that the suction ending angle needs to increase as well. Therefore, the leftward moving distance of the suction slide valve reduces with increase in condensing temperature. 


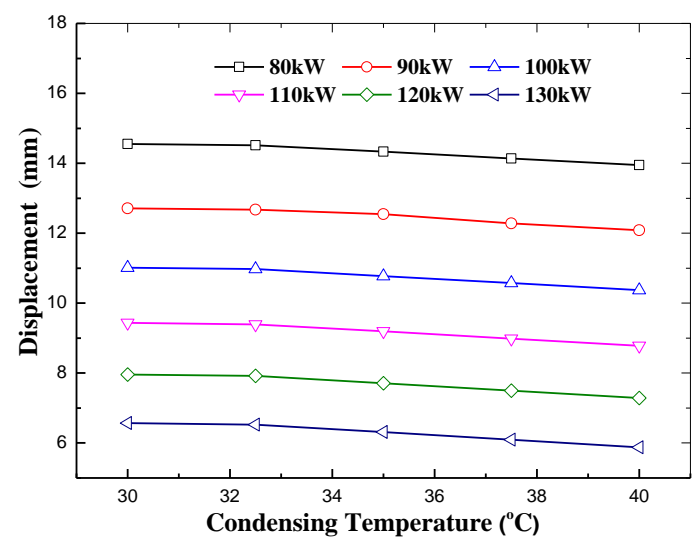

Figure 20. Displacement of suction slide valve vs. condensing temperature.

As illustrated in Figure 21, under the same condensing temperature, the leftward moving distance of the volume ratio slide valve decreases with the increase in waste heat availability. When waste heat availability increases under the same condensing temperature, the mass flow rate increases and the outlet volume flow rate of SSE increases. In order to obtain a fixed speed and prevent under-expansion and over-expansion, the discharge opening volume needs to increase. This means that the discharge starting angle needs to increase. Therefore, there is a decrease in the leftward moving distance of the volume ratio slide valve when the waste heat availability increases.

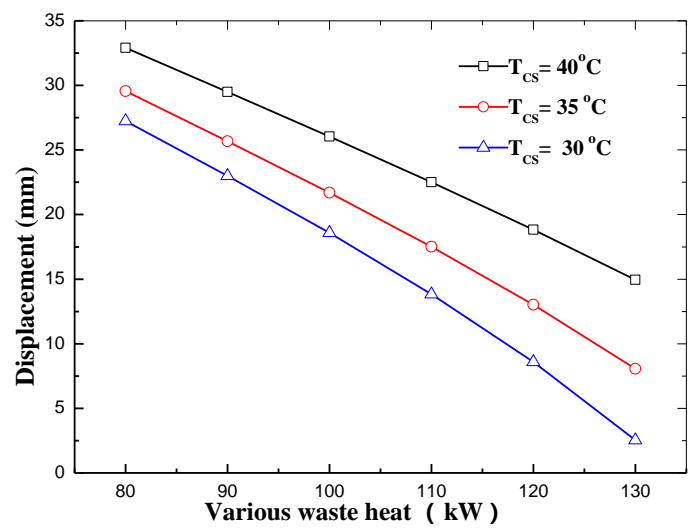

Figure 21. Displacement of volume ratio slide valve vs. various waste heat.

In Figure 22 it is indicated that, under the same waste heat conditions, the moving distance of the volume ratio slide valve increases with increase in condensing temperature. Under the same waste heat availability, when the condensing temperature increases, the back pressure of SSE increases. Thus the pressure ratio will decrease with increase of condensing temperature. In this study, the adiabatic index was set to a certain value. As shown in Equations (12) and (13), the volume ratio decreases with increase in condensing temperature. When the condensing temperature grows, the suction closure volume increases and causes the volume ratio decrease. However, the decrement cannot make optimum pressure ratio equal to the pressure ratio. Thus, the discharge opening volume also needs to decrease. The discharge starting angle needs to decrease to obtain a smaller discharge opening volume. Therefore, an increase in the leftward moving distance of the volume ratio slide valve occurs when the condensing temperature increases. 


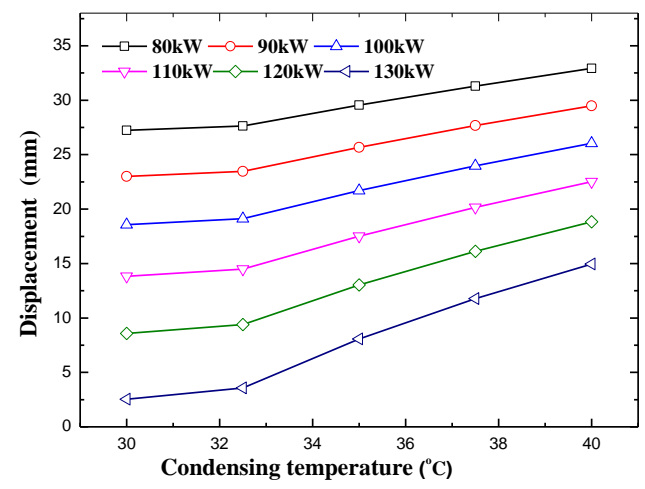

Figure 22. Displacement of the volume ratio slide valve vs. condensing temperature.

\section{Conclusions}

The purpose of this study was to provide a theoretical and technical basis for designing an SSE with a constant rotational speed and varied volume ratio to allow the expander to adapt to changing operating conditions. Therefore, the working principle of the slide valves in SSE has been fully described and a geometric analysis of suction/volume ratio slide valves was conducted to obtain the relations between slide valve displacement, suction closure volume, discharge opening volume, and volume ratio. Based on the description and geometric analysis of slide valves, a thermodynamic model of an ORC system based on SSE integrated with slide valves was designed to analyze the power output of SSE, the net power output of ORC and the variation rules of slide valve displacement under different operating conditions and different condensing temperatures.

From an example of an ORC system-based SSE with a $155 \mathrm{~mm}$ diameter screw rotor, it can be found that the power output and the net power output of the ORC with slide valves exhibits a significant improvement when compared with that of ORC without slide valves. It is also observed that the suction/volume ratio slide valve displacement changes approximately linearly with changing waste heat and changing condensing temperature. Hence the control strategy of slide valve can be easily used for SSEs. The proposed slide valves can be utilized to allow an SSE working at an optimum efficiency point under varied working conditions, which is of great importance in improving the power output for SSE and the net power output of ORC systems integrated with SSE under varied operation conditions.

Acknowledgments: The authors gratefully acknowledge the financial support provided by the National Basic Research Program of China under Grant Number 2013CB228306 and the International Science and Technology (S\&T) Cooperation Program of China under Grant Number 2014DF60600.

Author Contributions: Yuting Wu and Ruiping Zhi wrote the main part of the paper. Chongfang Ma and Biao Lei revised the paper. Jing-Fu Wang, Wei Wang, Guoqiang Li and Huan Wang provided useful suggestions and polished the paper. All authors read and approve the manuscript.

Conflicts of Interest: The authors declare no conflict of interest.

\section{Nomenclature}

$\dot{V}_{\text {in }} \quad$ volume flow rate at the inlet of SSE, $\left(\mathrm{m}^{3} / \mathrm{s}\right)$

$z_{1} \quad$ number of grooves of screw rotor, (-)

$z_{2} \quad$ number of teeth of the gate rotor, (-)

$n \quad$ rotational speed of SSE, (rpm)

$V_{\text {scv }} \quad$ suction closure volume of SSE, $\left(\mathrm{mm}^{3}\right)$

$V_{\text {dov }} \quad$ Discharge opening volume of SSE, $\left(\mathrm{mm}^{3}\right)$

$\theta_{\mathrm{se}} \quad$ suction ending angle, (rad)

$\theta_{\mathrm{ds}} \quad$ discharge starting angle, $(\mathrm{rad})$

$b \quad$ tooth width of gate rotor, $(\mathrm{mm})$

C center distance between the single-screw rotor and gate rotor, $(\mathrm{mm})$ 
$\mathrm{r}_{1} \quad$ radius of the screw rotor, $(\mathrm{mm})$

$\mathrm{r}_{2} \quad$ radius of the gate rotor, $(\mathrm{mm})$

$e \quad$ the minimum width of the groove rib

$\dot{Q}_{\mathrm{wf}} \quad$ heat transfer rate of the working fluid, $(\mathrm{kW})$

$\dot{Q}_{\mathrm{w}} \quad$ heat transfer rate of waste heat, $(\mathrm{kW})$

$\dot{m}_{\mathrm{wf}} \quad$ mass flow rate of working fluid, $(\mathrm{kg} / \mathrm{s})$

$h \quad$ enthalpy, $(\mathrm{kJ} / \mathrm{kg})$

$\dot{W}_{\text {sse }} \quad$ output power of SSE, $(\mathrm{kW})$

$\dot{W}_{\mathrm{p}} \quad$ power consumption of the pump, (kW)

$\dot{W}_{\text {net }} \quad$ net power output of the ORC system, $(\mathrm{kW})$

$\tau_{i} \quad$ volume ratio, (-)

$\eta_{\mathrm{s}} \quad$ shaft efficiency of the expander, (\%)

$\eta_{\mathrm{opt}} \quad$ the optimum shaft efficiency of the expander, (\%)

$\eta_{\mathrm{p}} \quad$ pump efficiency, $(\%)$

$r_{\mathrm{p}} \quad$ pressure ratio, (-)

$r_{\text {opt }} \quad$ optimum pressure ratio, (-)

Subscripts

$1,2,2 \mathrm{~s}$,

sate points in cycle (in Figure 11)

$3,4,5,5 \mathrm{~s}, 6$ sate points in cycle (in Figure 11)

Acronyms

ORC

SSE

organic Rankine cycle

single-screw expander

\section{References}

1. Wu, Y.T.; Ren, N.; Wang, T.; Ma, C.F. Experimental study on optimized composition of mixed carbonate salt for sensible heat storage in solar thermal power plant. J. Therm. Anal. Calorim. 2011, 85, 1957-1966. [CrossRef]

2. Younger, P.L. Geothermal Energy: Delivering on the Global Potential. Energies 2015, 8, 11737-11754. [CrossRef]

3. Heberle, F.; Brüggemann, D. Thermoeconomic analysis of hybrid power plant concepts for geothermal combined heat and power generation. Energies 2014, 7, 4482-4497. [CrossRef]

4. Cuellar, A.D.; Herzog, H. A Path Forward for Low Carbon Power from Biomass. Energies 2015, 8, $1701-1715$. [CrossRef]

5. Athari, H.; Soltani, S.; Rosen, M.A.; Mahmoudi, S.M.S.; Morosuk, T. Thermodynamic Analysis of a Power Plant Integrated with Fogging Inlet Cooling and a Biomass Gasification. Sustainability 2015, 7, 1292-1307. [CrossRef]

6. Saidur, R.; Rezaei, M.; Muzammil, W.K.; Hassan, M.H.; Paria, S.; Hasanuzzaman, M. Technologies to recover exhaust heat from internal combustion engines. Renew. Sust. Energ. Rev. 2012, 16, 5649-5659. [CrossRef]

7. Sprouse, C., III; Depcik, C. Review of organic Rankine cycles for internal combustion engine exhaust waste heat recovery. Appl. Therm. Eng. 2013, 51, 711-722. [CrossRef]

8. Capata, R.; Hernandez, G. Preliminary Design and Simulation of a Turbo Expander for Small Rated Power Organic Rankine Cycle (ORC). Energies 2014, 7, 7067-7093. [CrossRef]

9. Xie, Y.P. Prospect of application and development of Low saturation steam turbine. Energy Conversat. Technol. 2011, 29, 61-65.

10. Imran, M.; Usman, M.; Park, B.S.; Lee, D.H. Volumetric expanders for low grade heat and waste heat recovery applications. Renew. Sust. Energ. Rev. 2016, 57, 1090-1109. [CrossRef]

11. Antonelli, M.; Martorano, L. A study on the rotary steam engine for distributed generation in small size power plants. Appl. Energy 2012, 97, 642-647. [CrossRef]

12. Calise, F.; Capuano, D.; Vanoli, L. Dynamic Simulation and Exergo-Economic Optimization of a Hybrid Solar-Geothermal Cogeneration Plant. Energies 2015, 8, 2606-2646. [CrossRef]

13. Antonelli, M.; Baccioli, A.; Francesconi, M.; Desideri, U.; Martorano, L. Operating maps of a rotary engine used as an expander for micro-generation with various working fluids. Appl. Energy 2014, 113, 742-750. [CrossRef] 
14. Antonelli, M.; Baccioli, A.; Francesconi, M.; Martorano, L. Experimental and Numerical Analysis of the Valve Timing Effects on the Performances of a Small Volumetric Rotary Expansion Device. Energy Procedia 2014, 45, 1077-1086. [CrossRef]

15. Quoilin, S.; Lemort, V.; Lebrun, J. Experimental study and modeling of an Organic Rankine Cycle using scroll expander. Appl. Energy 2010, 87, 1260-1268. [CrossRef]

16. Chang, J.C.; Hung, T.C.; He, Y.L.; Zhang, W. Experimental study on low-temperature organic Rankine cycle utilizing scroll type expander. Appl. Energy 2015, 155, 150-159. [CrossRef]

17. Lemort, V.; Quoilin, S.; Cuevas, C.; Lebrun, J. Testing and modeling a scroll expander integrated into an Organic Rankine Cycle. Appl. Therm. Eng. 2009, 29, 3094-3102. [CrossRef]

18. Lemort, V.; Declaye, S.; Quoilin, S. Experimental characterization of a hermeti scroll expander for use in a micro-scale Rankine cycle. IMechE. Part A J. Power Energy 2012, 226, 126-136. [CrossRef]

19. Wang, H.; Peterson, R.B.; Herron, T.; Wang, H.; Peterson, R.B.; Herron, T. Experimental performance of a compliant scroll expander for an organic Rankine cycle. IMechE. Part A J. Power Energy 2009, 223, 863-872. [CrossRef]

20. Leibowitz, H.; Smith, I.K.; Stosic, N. Cost Effective Small Scale ORC Systems for Power Recovery from Low Grade Heat Sources. Int. Mech. Eng. Congr. Expo. (ASME) 2006, 521-527.

21. Lu, Y.; He, W.; Wu, Y.; Ji, W.; Ma, C.; Guo, H. Performance study on compressed air refrigeration system based onsingle screw expander. Energy 2013, 55, 762-768. [CrossRef]

22. Wang, W.; Wu, Y.T.; Ma, C.F.; Xia, G.D.; Wang, J.F. Experimental study on the performance of single screw expanders by gap adjustment. Energy 2013, 62, 379-384. [CrossRef]

23. Wang, W.; Wu, Y.T.; Ma, C.F.; Liu, L.D.; Yu, J. Preliminary experimental study of single screw expander prototype. Appl. Therm. Eng. 2011, 31, 3684-3688. [CrossRef]

24. He, W.; Wu, Y.; Peng, Y.; Zhang, Y.; Ma, C.; Ma, G. Influence of intake pressure on the performance of single screw expander working with compressed air. Appl. Therm. Eng. 2013, 51, 662-669. [CrossRef]

25. Zhang, Y.Q.; Wu, Y.T.; He, W.; Xia, G.D.; Ma, C.F.; Peng, Y.H. Experimental Study on the Influence of Rotational Speed on the Performance of a Single-screw Expander with a $175 \mathrm{~mm}$ Screw Diameter. Int. J. Green Energy 2015, 12, 257-264. [CrossRef]

26. Zhang, Y.Q.; Wu, Y.T.; Xia, G.D.; Ma, C.F.; Ji, W.N.; Liu, S.W.; Yang, K.; Yang, F.B. Development and experimental study on organic Rankine cycle system with single-screw expander for waste heat recovery from exhaust of diesel engine. Energy 2014, 77, 499-508. [CrossRef]

27. Desideri, A.; Gusev, S.; Martijn, V.D.B.; Lemort, V.; Quoilin, S. Experimental comparison of organic fluids for low temperature ORC (organic Rankine cycle) systems for waste heat recovery applications. Energy 2016, 97, 460-469. [CrossRef]

28. Glavatskaya, Y.; Podevin, P.; Lemort, V.; Shonda, O.; Descombes, G. Reciprocating Expander for an Exhaust Heat Recovery Rankine Cycle for a Passenger Car Application. Energies 2012, 5, 1751-1765. [CrossRef]

29. Qiu, G.; Liu, H.; Riffat, S. Expanders for micro-CHP systems with organic Rankine cycle. Appl. Therm. Eng. 2011, 31, 3301-3307. [CrossRef]

30. Li, J.; Pei, G.; Ji, J.; Bai, X.; Li, P.; Xia, L. Design of the ORC (organic Rankine cycle) condensation temperature with respect to the expander characteristics for domestic CHP (combined heat and power) applications. Energy 2014, 77, 579-590. [CrossRef]

31. Desideri, A.; Martijn, V.D.B.; Gusev, S.; Lemort, V.; Quoilin, S. Experimental campaign and modeling of a low capacity waste heat recovery system based on a single screw expander. In Proceedings of 22nd International Compressor Engineering Conference, West Lafayette, IN, USA, 14-17 July 2014; Purdue University: West Lafayette, IN, USA, 2014.

32. Wu, Y.T.; Lei, B.; Ma, C.F.; Zhao, L.; Wang, J.F.; Guo, H.; Lu, Y.W. Study on the Characteristics of Expander Power Output Used for Offsetting Pumping Work Consumption in Organic Rankine Cycles. Energies 2014, 7 , 4957-4971. [CrossRef]

(C) 2016 by the authors; licensee MDPI, Basel, Switzerland. This article is an open access article distributed under the terms and conditions of the Creative Commons Attribution (CC-BY) license (http://creativecommons.org/licenses/by/4.0/). 